\title{
Dancing with Sulfur: Simple Preparation and Properties of Thiacalix[n]thiophene Derivatives
}

\author{
Masashi Hasegawa* \\ * Department of Chemistry, Graduate School of Science, Kitasato University \\ 1-15-1 Kitasato, Sagamihara 252-0373, Japan
}

(Received June 30, 2020; E-mail: masasi.h@kitasato-u.ac.jp)

\begin{abstract}
In general, cyclization is the most crucial step in the synthesis of macrocyclic compounds formed out of repeated units of a $\pi$-system. However, a particular combination of aromatic wall unit and appropriate angular linkage can efficiently give cyclic compounds such as calix[n]arene and its analogues. This straightforward method allows material chemists to supply these compounds on multi-gram scale. Nevertheless, a more resourceful strategy is also required, because this simple approach is less feasible outside of specific combinations. Recently, we have newly developed a straightforward one-pot synthetic approach using a palladium coupling for a series of thiacalix[n]thiophene, thiacalix[n]dithieno[3,2-b:2, $\left.3^{\prime}-d\right]$ thiophene (thiacalix[n]DTT), and selenacalix[n]selenophenes, which are cyclic homologues of divalent chalcogen-bridged (S or Se) cyclic oligothiophene derivatives. A palladium-catalyzed reaction of $\left(\mathrm{Bu}_{3} \mathrm{Sn}\right)_{2} \mathrm{~S}$ or $\left(\mathrm{Bu}_{3} \mathrm{Sn}\right)_{2} \mathrm{Se}$ with dibromothiophene, dibromoselenophene, or diboromo-DTT derivatives led to effective cyclization in good yield. In the presence of appropriate substituents, this method seems to kinetically favor the formation of macrocycles. The molecular and physical properties, including $\mathrm{X}$-ray analysis, absorption spectra and redox properties, of the resultant macrocycles were also described. Unlike conventional calixarenes, they possess electron-donating ability, exhibiting multielectron redox processes due to electron delocalization. Thiacalix[n]DTT derivatives $(\mathrm{n}=4-6)$ acted as a cavitand for $\mathrm{C}_{60}$ molecules; the cyclic 4-mer formed a 1:2 complex in the solid state, while the 5- and 6-mer formed 1:1 complexes in solution. Furthermore, thiacalix[4]thiophene and selenacalix[n]selenophene having tert-butylphenyl groups exhibit gelling behavior in toluene, despite the absence of any hydrogen binding sites. Intermolecular chalcogen ( $\mathrm{S}$ or $\mathrm{Se}$ ) interactions facilitate the self-assembly that results in this gel formation.
\end{abstract}

\section{Introduction}

Calix[n]arene and its analogues have been some of the most extensively studied macrocyclic arenes, leading to wideranging applications in material, environmental, and biological chemistry. ${ }^{1,2}$ To date, a diverse range of calix[n]arenes and modified calix[n]arenes have been prepared. ${ }^{3}$ Among them, thiacalix[n]arene and its derivatives, composed of cyclic phenolic units linked with divalent sulfur, are known as an analogue of calix[n]arenes (Figure 1). The longer carbon-sulfur bonds of the bent thioether moieties allow formation of a larger cavity and provide higher conformational flexibility compared to methylene-linked calix[n]arenes. ${ }^{5}$ This structural difference can be favorable for the creation of the sophisticated conformations seen in host-guest chemistry. However, examples of the preparation and evaluation of the thiacalix[n]arene family are limited due to the lack of appropriate synthetic methods. $^{6-8}$

In the synthesis of macrocyclic arenes, cyclization is the most crucial step. ${ }^{9}$ Typically, well studied macrocyclic arenes, such as calix[n]arenes, ${ }^{1-3}$ resorcarene, ${ }^{10}$ and pillar[n]arene, ${ }^{11}$ among others, can be prepared by a substitution reaction with the aid of reactive hydroxyl-, or methoxy-substituted aromatic rings (Scheme 1a). These compounds may not only be candidate functionalized materials, but also provide a fundamental scaffold for further $\pi$-extended compounds. ${ }^{12}$ However, only a limited number of macrocyclic arenes with such substituents are accessible to material chemists. Because of this, development of alternative synthetic methods for the creation of novel macrocyclic arenes is a highly sought-after goal.
Thiacalix[n]thiophene (1a) and its derivatives are a particular class of thiacalix[n]arenes whose phenolic units are replaced by thiophene. This combination of thiophene and sulfide linker can offer promising redox properties for further functionalization. They can also be considered as sulfidebridged cyclic thiophene oligomers, in which the S-thiophene$\mathrm{S}$ subunits may serve as an electron-rich macrocycle for forming host-guest complexes with electron-deficient molecules or metal ions. The first synthesis of thiacalix[n]thiophene was accomplished by two groups independently (Scheme 1b). In 1997, König and co-workers prepared it by the reaction of lithiated thiophene with $\mathrm{SCl}_{2}$ in a yield of less than $1 \%{ }^{13}$ Although they confirmed its structure by $\mathrm{X}$-ray analysis, other spectral properties were not investigated. At almost the same time, Nakayama and co-workers reported a more practical stepwise synthesis by cyclization of acyclic precursors. ${ }^{14,15}$ Although this approach allows the study of fundamental properties, it is still insufficient for further investigation into hostguest chemistry, electrochemical properties, supramolecular properties, and so on. In order to open new avenues for further intriguing applications of thiacalix[n]thiophenes, it is necessary to improve their accessibility, and provide structural diversity. Keeping this in mind, our group decided to develop the chemistry of various types of thiacalix[n]thiophene $(\mathbf{1}-\mathbf{3})^{16,17}$ and thiacalix[n]dithieno[3,2-b:2',3'-d] thiophene (thiacalix[n]DTT, 4-10). ${ }^{18}$ In addition, we applied our methods to selenium-containing analogues: selenacalix[n]selenophene $(\mathbf{1 1 - 1 3})^{19}$ and selenacalix[4]DTT (14) (Figure 1b). ${ }^{20}$ In this review, we describe a facile protocol for the synthesis of these macrocycles using a one-pot $\mathrm{Pd}$-catalyzed coupling. We also 
(a)

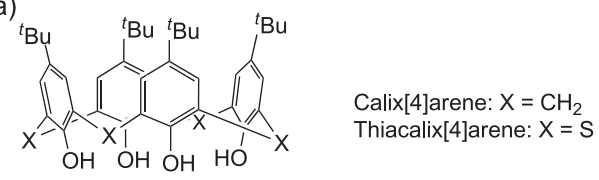

(b)
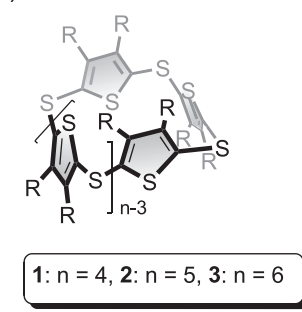

$\mathbf{a}(\mathrm{R}=\mathrm{H}), \mathbf{b}\left(\mathrm{R}=\mathrm{CH}_{3}\right)$ c $\left(\mathrm{R}={ }^{n} \mathrm{Bu}\right)$

$\mathrm{d}(\mathrm{R}=\longrightarrow \mathrm{Bu})$

$\mathbf{e}(\mathrm{R}=$

$f\left(R=-\mathrm{CH}_{3}\right)$

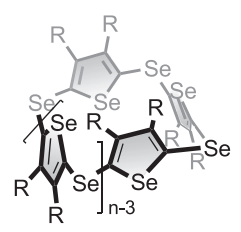

$\left(\mathrm{R}=-\left(-{ }^{\mathrm{t}} \mathrm{Bu}\right)\right.$

11: $n=4,12: n=5,13: n=6$

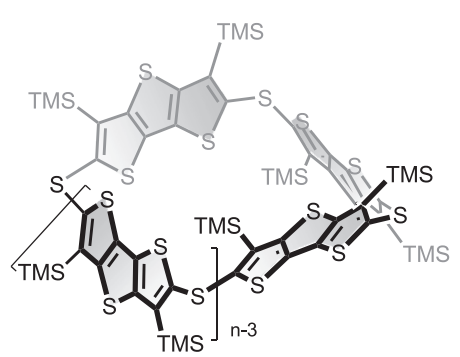

Thiacalix[n]dithienothiophene (Thiacalix[n]DTT)

4-10

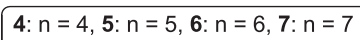

8: $n=8,9: n=9,10: n=10$

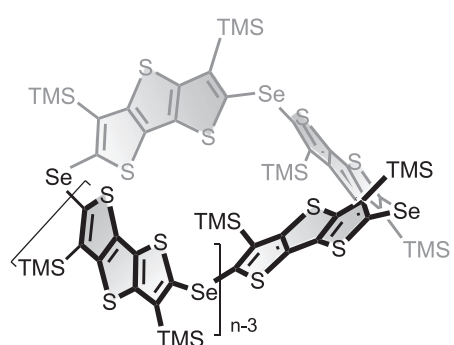

14

Figure 1. Molecular structures of (a) calix[4]arenes and (b) thiacalix[n]thiophene 1-3, thiacalix[n]DTT 4-10, and their selenium isologues 11-14.

investigated molecular structures, electrochemical properties, and complexation behavior. In addition, some macrocycles exhibited gelling behavior in toluene, despite the absence of any hydrogen bonding sites. The details of these interesting phenomena are also discussed.

\section{One-pot Synthesis of Thiacalix[n]thiophene Derivatives}

\subsection{Thiacalix[n]thiophene}

A number of diaryl sulfides (Ar-S-Ar) have been synthesized by using nucleophilic displacement on aryl halides with aromatic thiols, ${ }^{21}$ or the reaction of aryl halides with an elemental sulfur source catalyzed by nickel, ${ }^{22,23}$ copper, ${ }^{24}$ iron, ${ }^{25}$ or cobalt, ${ }^{26}$ and among others. However, these known couplings gave only main products having an acyclic structure. To establish a versatile synthetic method for thiacalix[n]thiophenes, we sought an answer as to how to achieve a metal-catalyzed coupling of thiophene and elemental sulfur as the corner unit. We envisioned that thanks to the typical bond angle of $\mathrm{C}-\mathrm{S}-\mathrm{C}$, which approaches $90^{\circ}$, geometrical constraints might contribute to setting up a pre-organized intermediate for macrocycle formation. In fact, some cyclic thioethers having electron deficient aromatic rings, and which are also analogues of thiacalix[n]arene, had been successfully prepared by a nucleophilic substitution based on this strategy. ${ }^{7,8}$ After several attempts, we found that $\mathrm{C}-\mathrm{S}$ bond formation using diboromothiophene derivatives and tributyltinsulfide $\left(\left(\mathrm{Bu}_{3} \mathrm{Sn}\right)_{2} \mathrm{~S}\right)$ in the presence of $\mathrm{Pd}\left(\mathrm{PPh}_{3}\right)_{4}$ successfully gave thiacalix[n]thiophenes

Scheme 1. Synthesis of calix[4]arene and thiacalix[4]arene analogues.

(a) Typical synthesis of calix[4]arene and thiacalix[4]arene

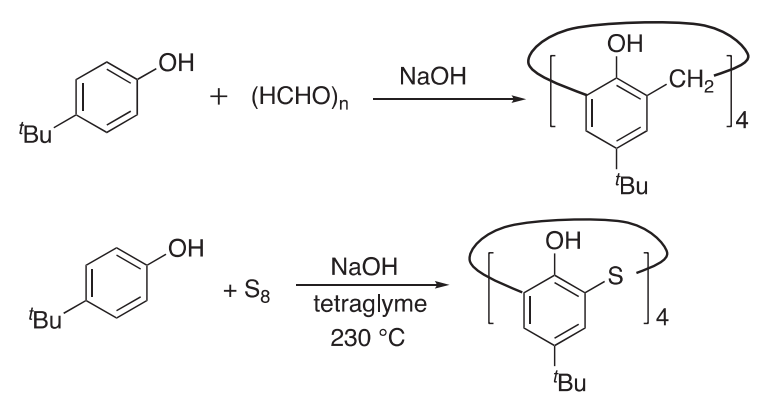

(b) Synthesis of thiacalix[4]thiophene

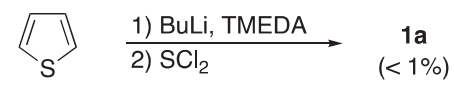

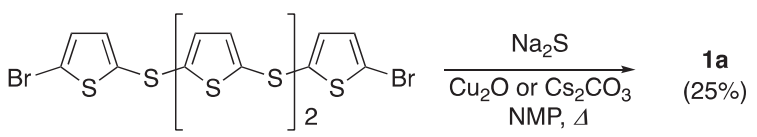

(c) This work

$$
\begin{aligned}
& \text { } \\
& \text { 獃 }
\end{aligned}
$$

$(n=4-6)$ (Table1). While this kind of coupling was originally developed by Kosugi and Migita in 1985 for the preparation of symmetrical/nonsymmetrical diarylsulfides, ${ }^{27}$ it was found that cyclic compounds were obtained preferentially depending on the exact conditions applied.

The results of cyclization with various 2,5-dibromo-3,4disubstituted thiophene are summarized in Table 1. Under typical conditions, an equimolar amount of $\left(\mathrm{Bu}_{3} \mathrm{Sn}\right)_{2} \mathrm{~S}$ and dibromothiophene, and $\mathrm{Pd}\left(\mathrm{PPh}_{3}\right)_{4}(12 \mathrm{~mol} \%)$ were employed in DMF $(20 \mathrm{mM})$. The products, cyclic homologues, were separated by using size-exclusion gel permeation chromatography (GPC).

To begin with, we chose 2,5-dibromothiophene as the starting material for the cyclization (Table 1, entry 1). Yet, only acyclic thienylene-sulfide molecules were obtained as a product in low yield. On the other hand, when 2,5-dibromo-3,4-

Scheme 2. Synthesis of thiacalix[n]thiophene derivatives via palladium-catalyzed coupling reaction.
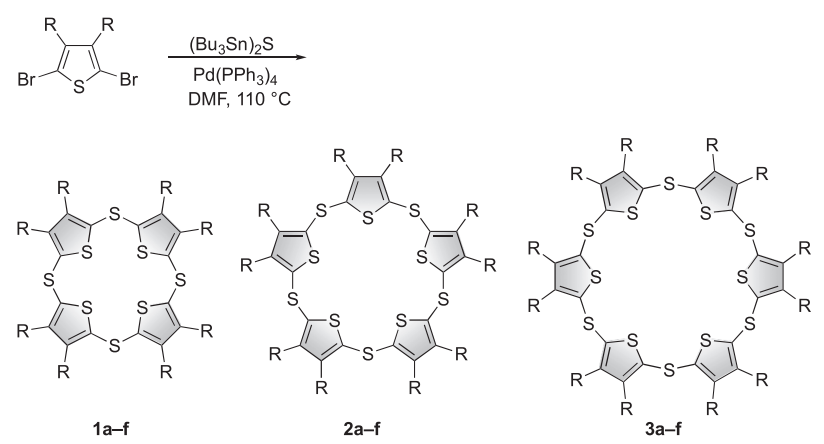
Table 1. Cyclization of 2,5-dibromothiophene derivatives with $\left(\mathrm{Bu}_{3} \mathrm{Sn}\right)_{2} \mathrm{~S}^{a}$

\begin{tabular}{ccccc}
\hline Entry & $\mathrm{R}$ & \multicolumn{3}{c}{ Product, yield [\%] } \\
& & $n=4$ & $n=5$ & $n=6$ \\
\hline $1^{c}$ & $\mathrm{H}$ & - & - & - \\
2 & $\mathrm{CH}_{3}$ & $\mathbf{1 b}, 7$ & $\mathbf{2 b}, 3$ & - \\
$3^{d}$ & $\mathrm{Bu}$ & $\mathbf{1 c}, 27$ & $\mathbf{2 c}, 11$ & $\mathbf{3 c}, 5$ \\
4 & & $\mathbf{1 d}, 27$ & $\mathbf{2 d}, 6$ & $\mathbf{3 d}, 5$ \\
6 & & $\mathbf{1 e}, 26$ & $\mathbf{2 e}, 8$ & $\mathbf{3 e}, 2$ \\
& & & & \\
\hline
\end{tabular}

${ }^{a}$ Reaction conditions: [thiophene $] /\left[\left(\mathrm{Bu}_{3} \mathrm{Sn}\right)_{2} \mathrm{~S}\right] /\left[\mathrm{Pd}\left(\mathrm{PPh}_{3}\right)_{4}\right]=$ 0.5:0.5:0.06 mmol in DMF $25 \mathrm{~mL}$ at $110{ }^{\circ} \mathrm{C}$ under Ar. ${ }^{b}$ Isolated yield after GPC separation. ${ }^{c}$ Only acyclic products were obtained. ${ }^{d}$ Trace amount of cyclic 7-mer was obtained.

dimethylthiophene was employed as the aromatic unit, we obtained a small amount of cyclic tetramer, thiacalix[4]thiophene derivative $\mathbf{1 b}(7 \%)$ and pentamer, thiacalix[5]thiophene derivative $\mathbf{2 b}(3 \%)$ as the major products (entry 2$)$. Furthermore, when we used 2,5-dibromo-3,4-dibutylthiophene, the conversion to macrocyclic products was dramatically improved; cyclic tetramer (1c), pentamer (2c), and hexamer (3c) were obtained in $27 \%, 11 \%$, and $5 \%$ yields, respectively, together with a trace amount of cyclic heptamer after GPC separation (entry 3). This increase in isolated yield of the cyclic products implies that the bulkiness of the substituents on the thiophene affects the cyclization. In other words, larger substituents might promote cyclization due to suppression of conformational flexibility during elongation of the acyclic intermediate. In a similar manner, reactions that started with 2,5-dibromo-4,5-bis(4-butylphenyl)thiophene and 2,5dibromo-4,5-bis(4- $t$-butylphenyl)thiophene, in which the alkyl phenyl groups are considered to be moderately bulky substituents, led to the corresponding cyclic compounds (1d3d and $\mathbf{1 e - 3 e )}$ in moderate yield (Table 1, entries 4 and 5). On the other hand, when tolyl groups were employed as the substituents, 1 f was obtained in $8 \%$ together with trace amount of 2f. Compounds 1 ff and $\mathbf{2 f}$ was hardly soluble in common organic solvents, and therefore the solubility of the macrocycle might also be critical to the yield.

\subsection{Thiacalix[n]dithienothiophene}

The use of $\pi$-extended components in the cyclization can afford a macrocycle having a spacious three-dimensional (3D) cavity that can encapsulate a large molecule. To this end, a 2,6dibromodithieno[3,2- $\left.b: 2^{\prime}, 3^{\prime}-d\right]$ thiophene $(2,6 \text {-dibromo-DTT })^{28}$ was employed as the building component. DTT is composed of three annulated thiophenes, and has been widely utilized to construct functional materials, such as p-type semiconductors and photosensitizers. ${ }^{29}$

An efficient cyclization to larger macrocycles was accomplished when 2,6-dibromo-3,5-bis(trimethylsilyl)DTT (18), which is prepared from 3-boromothiophene in four steps (Scheme 3), was employed as starting material. ${ }^{30}$ It underwent coupling reaction cleanly at $20 \mathrm{mM}$ in toluene to give different sized cyclic oligomers: 4 (43\%), $5(19 \%)$, and $6(8 \%)$ together with larger cyclic homologues (7-10) after GPC separation. When the reaction was carried out at $40 \mathrm{mM}$ (entry 2; Table 1), only $4 \%$ of 4 was obtained, together with acyclic compounds. In addition, a certain amount of the cyclic compounds were formed under diluted condition $(10 \mathrm{mM})$, although the total

Scheme 3. Synthesis of dibromo-bis(TMS)-DTT (18).

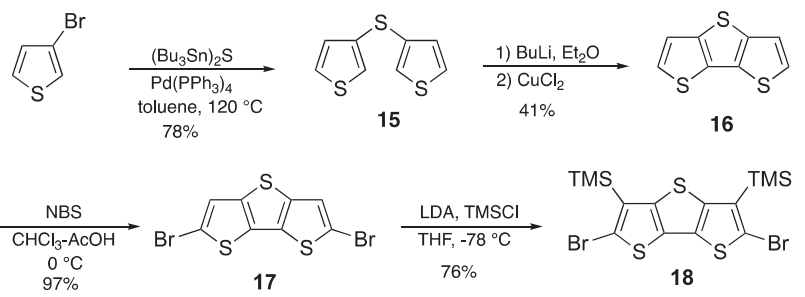

Table 2. Synthesis of thiacalix[n]DTT 4-6 and higher cyclic oligomers under various conditions. ${ }^{a}$

\begin{tabular}{ccccccc}
\hline \multirow{2}{*}{ Entry } & Solvent & $\begin{array}{c}\text { Conc. } \\
(\mathrm{mM})\end{array}$ & Temp. & $\mathbf{4}$ & $\mathbf{5}$ & $\mathbf{6}$ \\
\hline $1^{c}$ & toluene & 20 & reflux & 43 & 19 & 8 \\
2 & toluene & 40 & reflux & 4 & - & - \\
3 & toluene & 10 & reflux & 16 & 11 & 8 \\
4 & 1,4-dioxane & 20 & reflux & 31 & 12 & 16 \\
5 & THF & 20 & reflux & 9 & 5 & 4 \\
6 & NMP & 20 & $120^{\circ} \mathrm{C}$ & 59 & 9 & 5 \\
7 & DMF & 20 & $120^{\circ} \mathrm{C}$ & 56 & - & - \\
8 & DMF/toluene ${ }^{d}$ & 20 & $120^{\circ} \mathrm{C}$ & 77 & 5 & 2 \\
\hline
\end{tabular}

${ }^{a}$ Reaction conditions: $[18] /\left[\left(\mathrm{Bu}_{3} \mathrm{Sn}\right)_{2} \mathrm{~S}\right] /\left[\mathrm{Pd}\left(\mathrm{PPh}_{3}\right)_{4}\right]=0.5: 0.5: 0.06 \mathrm{mmol}$ under Ar. ${ }^{b}$ Isolated yield after GPC separation. ${ }^{c}$ Larger macrocycles 7 (4\%), $8(4 \%), 9(1 \%)$, and 10 (trace) were also isolated. ${ }^{d} \mathrm{v} / \mathrm{v}=1: 1$.

Scheme 4. Synthesis of 4-mer (4), 5-mer (5), 6-mer (6), and higher oligomers (7-10).

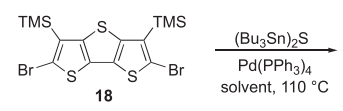

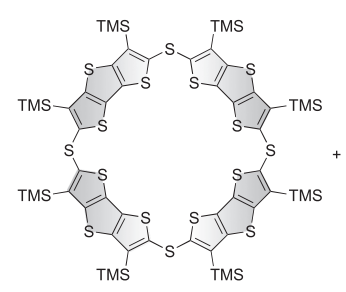

4

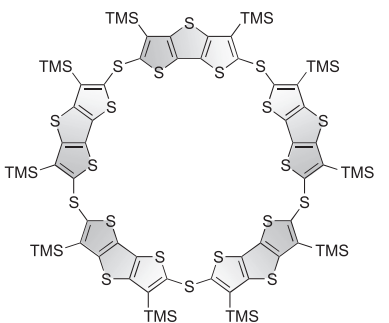

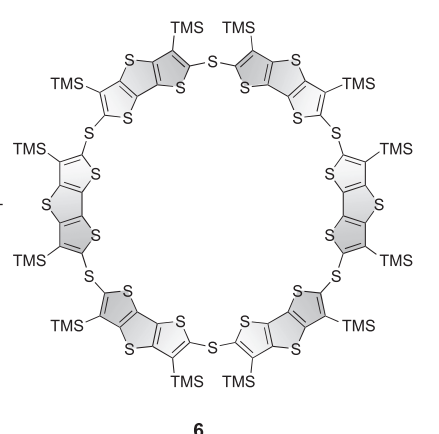

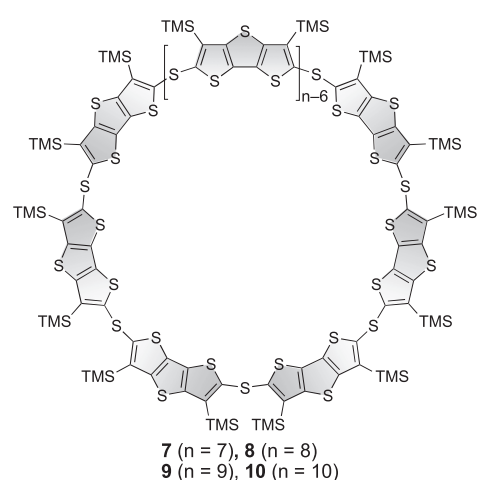

$7(n=7), 8(n=8)$
$9(n=9), 10(n=10)$ 
yield of the reaction was low (entry 3 ). In 1,4-dioxane at $20 \mathrm{mM}$ concentration, the cyclic compounds also formed preferentially (entry 4). Contrary to this, the reaction in THF gave a relatively lower yield than that in toluene (entry 5). In this case, an acyclic composite of lower molecular weight was afforded, and so the reaction did not proceed well at reflux temperature in THF. The reaction in $N$-methylpyrrolidone (NMP) preferentially gave cyclic products (entry 6). Interestingly, the reaction performed in DMF solution led to only cyclic tetramer 4 in 56\% yield (entry 7). In this case, an insoluble precipitate of $\mathbf{4}$ was observed during the reaction. This may prevent the formation of larger cyclic products in the catalytic cycle. When the reaction was carried out in a 1:1 mixture of $\mathrm{DMF} /$ toluene solution, compound $\mathbf{4}$ was obtained in the best yield, and highest total conversion to the cyclic homologues (entry 8)

In sharp contrast, when the identical cyclization conditions were applied to unsubstituted 2,6-dibromo-DTT, no cyclic product was obtained, possibly due to conformational flexibility of the reaction intermediates caused by the absence of bulky TMS groups.

\subsection{Mechanism to Macrocycles}

As described above, the trend in yield of the cyclic products in each coupling reaction implied that the substitutions on the thiophene/DTT plays an important role in the cyclization process. Density functional theory (DFT) calculations at B3LYP/6-31G(d,p) level indicated that a substructure of the cyclic compounds, 2,2'-thiobis-DTT derivative 19, preferred an angular conformation with an anti-arrangement (Scheme 5a). This geometry is the result of steric hindrance due to the TMS groups, and the intrinsic geometry of the $\mathrm{C}-$ $\mathrm{S}-\mathrm{C}$ bond; the dihedral angle of $\mathrm{C}(2)-\mathrm{C}(1)-\mathrm{C}\left(1^{\prime}\right)-\mathrm{C}\left(2^{\prime}\right)$ and bond angle of $\mathrm{C}(1)-\mathrm{S}(1)-\mathrm{C}\left(1^{\prime}\right)$ were calculated to be $179^{\circ}$ and $104^{\circ}$, respectively, in the most stable conformation. Hence, a zig-zag conformation with anti-arrangement of all adjacent thiophene subunits may be found in the acyclic elongated intermediate (20-i, Scheme 5b). This zig-zag intermediate has

Scheme 5. (a) Optimized geometry of 19 by DFT calculations (B3LYP/6-31G(d,p). (b) Schematic illustration of possible intermediates leading to the cyclic compound.

(a)
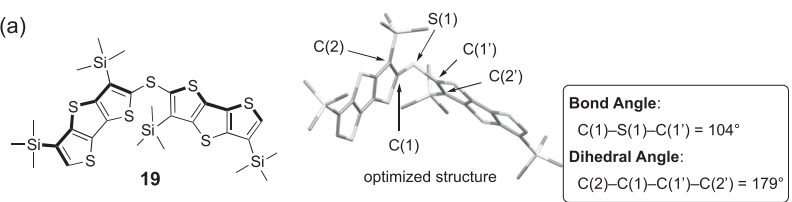

(b)
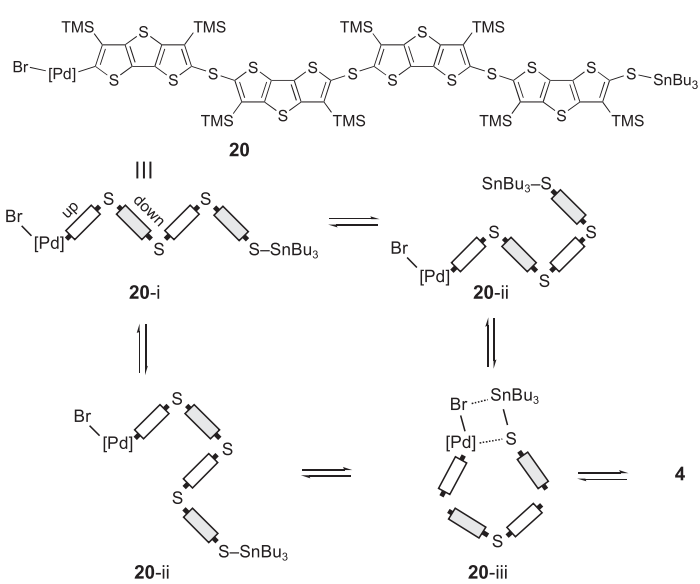

a great opportunity to undergo ring closure after a single rotation of any two bonds between a carbon of DTT and divalent sulfur to give 20-iii. The resulting intramolecular transmetalation process, possibly supported by palladium-sulfur interactions, can easily provide the cyclic tetramer of $\mathbf{4}$ after reductive elimination of palladium.

\section{Molecular Structures}

It is well known that calix[4]arene can adopt four stable conformers: cone, partial cone, 1,2-alternate, and 1,3-alternate. These four conformers are freely interconvertible in solution, with the methylene linkers acting as a flexible hinge. As such, unsubstituted thiacalix[n]thiophene is also expected to be flexible in solution. On the other hand, thiacalix[n]thiophene and thiacalix[n]DTT bearing large substituents at their $\beta$-positions prefer a 1,3-alternate conformer to avoid steric repulsion. Figure 2a illustrates optimized geometries of 1f. The molecular conformation having thiophene rings in a syn-arrangement is not allowed as a stable geometry due to steric hindrance, and therefore some conformers contain horizontal thiophene moieties instead of the syn-arrangement.

For DTT derivatives (4), only two stable conformers were found from DFT calculations. Similar to 1f, a conformer close to a 1,3-alternate geometry is the most stable (Figure 2b). The other stable conformer consists of two opposite DTTs connected horizontally to the cavity. No other stable conformers were found during the optimization procedure. The latter conformer possesses a much higher energy compared to that of the 1,3-alternate geometry, in fact $37 \mathrm{kJmol}^{-1}$ higher, because of the steric factor of two TMS groups on each DTT ring.

(a)
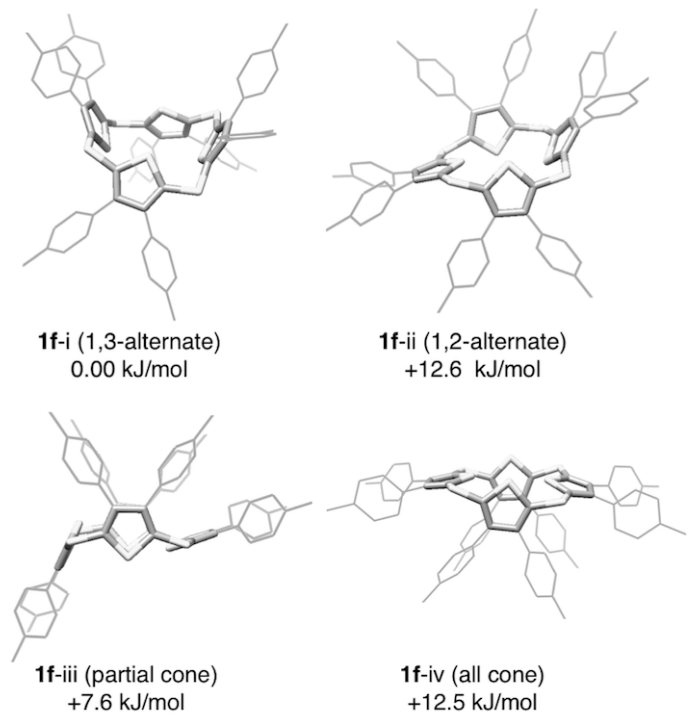

(b)
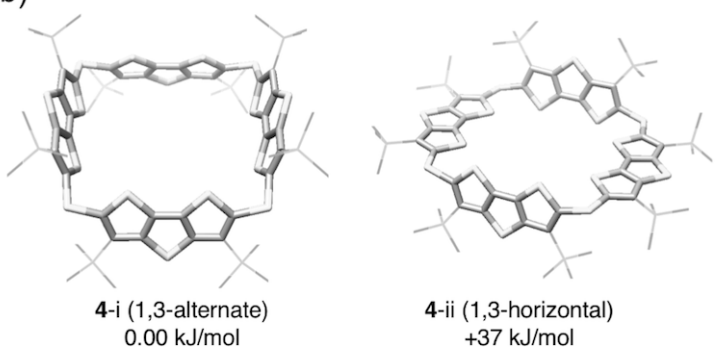

Figure 2. Optimized geometry and relative energy by DFT calculations (B3LYP/6-31G(d,p)) of (a) 1f and (b) 4. 
The structures of cyclic compounds $\mathbf{4}$ and $\mathbf{5}$ were also unambiguously determined by $\mathrm{X}$-ray analysis (Figure 3a). Compound 4 crystallizes in tetragonal space group $I 4_{1} / \mathrm{a}$ with four chlorobenzene molecules. It adopts a highly symmetrical structure whose four DTT rings and sulfur linkage atoms are crystallographically identical under $S_{4}$ improper rotation. Thus, the macrocyclic molecule has a 1,3-alternate geometry, in which adjacent DTT units are connected in an anti-arrangement through the $\mathrm{C}-\mathrm{S}-\mathrm{C}$ bond. This molecular geometry is quite similar to the most stable molecular conformation obtained for $\mathbf{4}$ from DFT calculations. Compound $\mathbf{4}$ has a large quadrilateral cavity in which the diagonal distance was estimated to be $12.8 \AA$, and the shortest distance between the two DTT rings facing each other was calculated to be $8.4 \AA$. Although there are no significant van der Waals contacts through sulfur atoms in the packing diagram, compound $\mathbf{4}$ forms a channel-like columnar alignment with $\mathrm{PhCl}$ molecules. However, when the solvent was removed in vacuo, the crystal collapsed immediately.

The crystal structure of $\mathbf{5}$ revealed a folded, envelop-like shape (Figure $3 \mathrm{c}$ and $\mathrm{d}$ ). There are large void spaces within the macrocycles with diagonal $\mathrm{S} \cdots \mathrm{S}$ distances of $13.2-15.6 \AA$. Compound 5 consists of an odd number of DTT rings, and hence cannot adopt an alternate structure such as the 1,3alternate conformer found in $\mathbf{4}$. As a result, an adjacent pair of
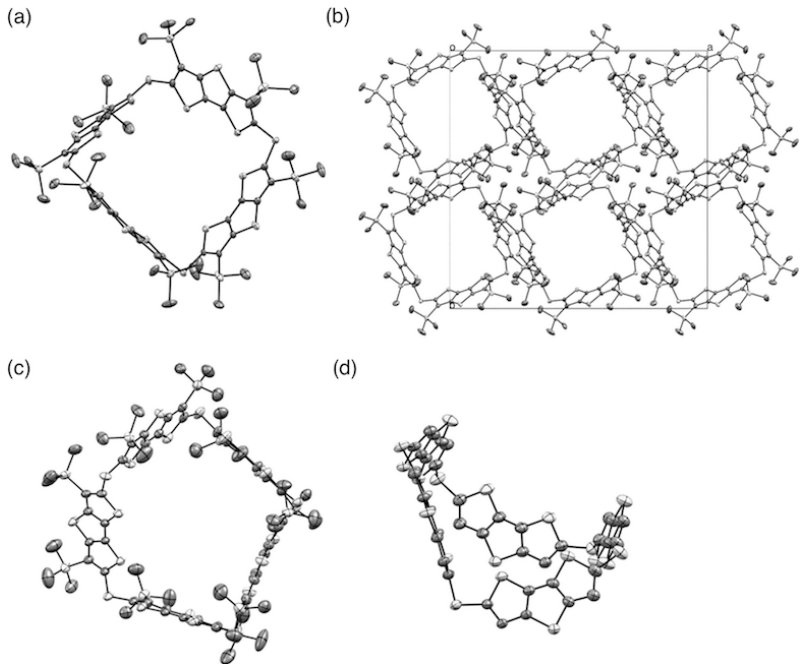

(d)

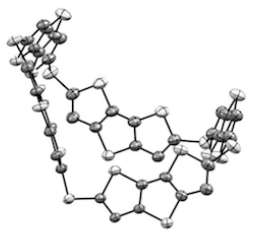

Figure 3. X-ray crystal structure of (a), (b) 4 and (c), (d) 5 . the five DTT rings were linked almost perpendicular with respect to each other.

The molecular structure of $\mathbf{6}$ was evaluated by DFT calculations because we could not obtain single crystals suitable for $\mathrm{X}$-ray analysis. Comparing the calculated structures of $\mathbf{6}$ and 5 , a clear difference based on the parity of $n$ in thiacalix[n]DTT was found; a hexagonal alternate geometry in $\mathbf{6}$ was found to be the most stable conformer: this avoids TMS groups interacting, whereas a folded pentagonal geometry, close to the crystal structure, was obtained for 5. Thus, the HOMO and LUMO of 6 were spread over the whole molecule through divalent sulfur linkage atoms, while those of $\mathbf{5}$ localize on some DTT units of the macrocycles in an envelope geometry (Figure 4a, b).

\section{Electronic Spectra}

The trends in electronic (UV/Vis) spectra were almost the same for both the thiacalix[n]thiophene (1-3) and thiacalix[n]DTT (4-7) series. Figure 4c shows the electronic spectra of the homologues 4-7, together with reference compound 22 (Scheme 6). All homologues exhibit very similar spectral shape, (a)

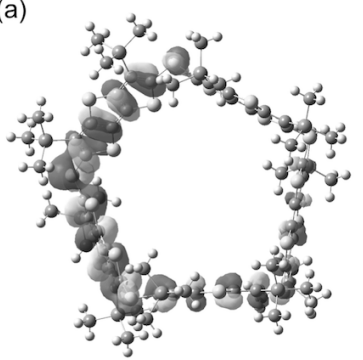

(b)

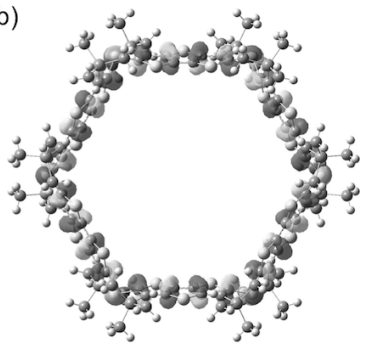

(c)

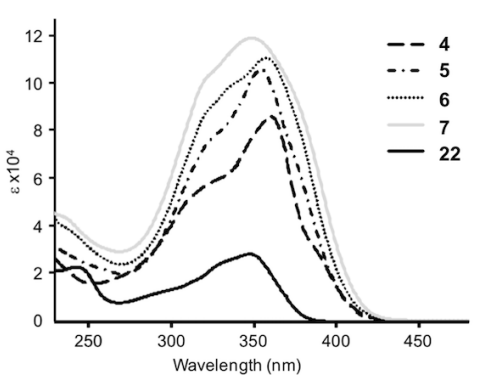

Figure 4. HOMO on the optimized molecular geometry of (a) 5 and (b) 6. (c) Electronic spectra of 4-7 and reference compound 22 in $\mathrm{CH}_{2} \mathrm{Cl}_{2}$.

Scheme 6. (a) Molecular structure of 21, and possible redox process of (b) 22 and (c) 4 in CV measurements.

(a)

(b)<smiles>Brc1c(Sc2ccccc2)sc(Sc2ccccc2)c1Br</smiles>

21

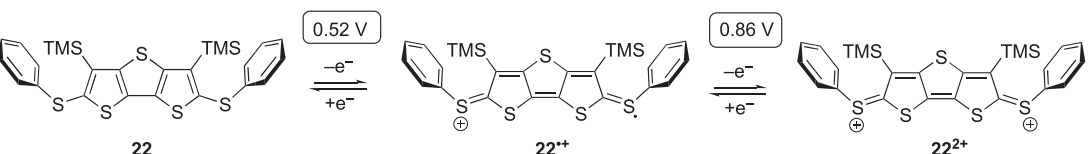

(c)

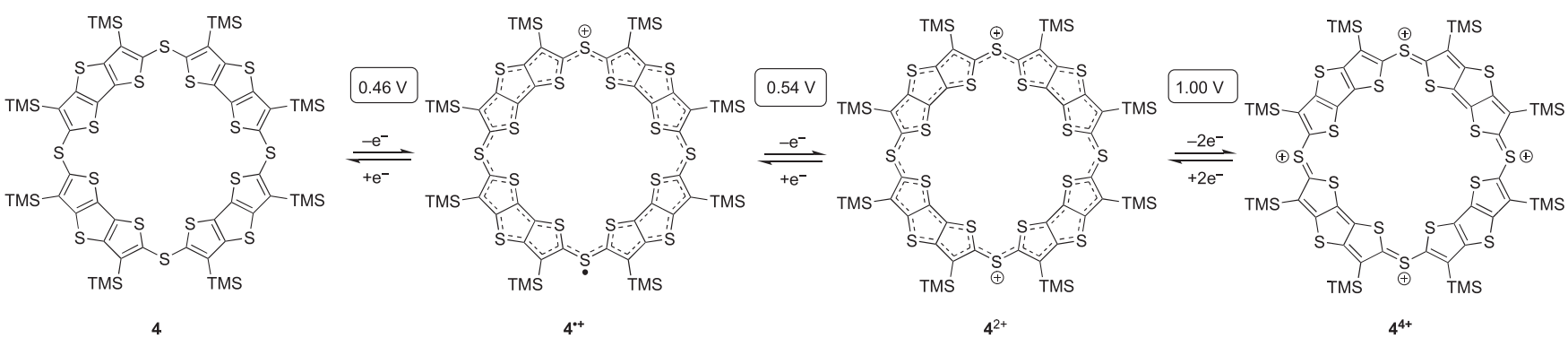


but differ in intensity. The spectra contain roughly two absorption bands. The maxima of the longest absorption band were as follows: $\mathbf{4}(360 \mathrm{~nm}), \mathbf{5}(355 \mathrm{~nm}), \mathbf{6}(358 \mathrm{~nm})$, and 7 (349 nm). These are slightly red-shifted or similar compared with that of $22(348 \mathrm{~nm})$. The observed small bathochromic shifts are owing to the conjugation of the DTT units of each macrocycle though sulfur bridges.

\section{Redox Properties}

Since the present macrocycles can be thought of as thioethers, a class that behaves as excellent electron donors, intriguing electrochemical properties derived from the cyclic structure can be anticipated. As expected, cyclic voltammetry (CV) and differential pulse voltammetry (DPV) analyses exhibit obvious multi redox waves in the lower potential region. Table 3 summarizes the oxidation potentials of 1c-3c, 4-7, 21, and $\mathbf{2 2}$ obtained by DPV measurements. Compound $\mathbf{1 c}$ showed two pairs of reversible redox waves $(0.50$ and $0.78 \mathrm{~V}$ vs. Fc/ $\mathrm{Fc}^{+}$), although reference compound 21 exhibited two irreversible redox waves at higher potential (0.62 and $1.13 \mathrm{~V})$. Considering their ring size, potentials $E_{1}$ and $E_{2}$ could be assigned to the formation of $1 \mathbf{c}^{\cdot+}$ and $\mathbf{1} \mathbf{c}^{2+}$, respectively.

Table 3. Oxidation potentials of $1 c-3 c, 4-7,21$, and 22 .

\begin{tabular}{ccccccc}
\hline Compd & $E_{1}$ & $E_{2}$ & $E_{3}$ & $E_{4}$ & $E_{5}$ & $E_{6}$ \\
\hline $\mathbf{1 c}$ & 0.50 & 0.78 & - & - & - & - \\
$\mathbf{2 c}$ & 0.57 & 0.80 & 0.97 & - & - & - \\
$\mathbf{3 c}$ & 0.53 & 0.85 & 1.02 & - & - & - \\
$\mathbf{2 1}$ & 0.62 & 1.13 & - & - & - & - \\
\hline $\mathbf{4}$ & 0.46 & 0.54 & 1.00 & - & - & - \\
$\mathbf{5}$ & 0.50 & 0.61 & 0.76 & 0.98 & 1.21 & - \\
$\mathbf{6}$ & 0.43 & 0.65 & 0.83 & 0.96 & 1.10 & 1.25 \\
$\mathbf{7}$ & 0.50 & 0.71 & 0.82 & 0.95 & 1.03 & 1.23 \\
$\mathbf{2 2}$ & 0.52 & 0.86 & - & - & - & - \\
\hline
\end{tabular}

${ }^{a}$ all potentials were obtained from DPV in 1,2-dichloroethane at $25^{\circ} \mathrm{C}$ with $\mathrm{Bu}_{4} \mathrm{NPF}_{6}$.

The lowering of $E_{1}$ and $E_{2}$ in 1c compared with those of $\mathbf{2 1}$ implies the resulting cationic species can be stabilized by charge delocalization over sulfide linkers in the former. On the other hand, $2 \mathrm{c}$ showed three redox waves, whose potentials are slightly higher than those of 1c. This positive shift is presumably due to the less conjugated structure derived from the folded geometry of $\mathbf{2 c}$. Indeed, the oxidation potentials of $\mathbf{3 c}$ were lowered compared with the corresponding values for $\mathbf{2 c}$.

Compound 4-7 and 22 also exhibit reversible multi-redox processes (Figure 5). The potentials are much lower than those of thiacalix[n]thiophenes due to the DTT units. In compound 4, three reversible redox waves were observed at $0.46,0.54$, and $1.00 \mathrm{~V}$, while there were two reversible waves in compound 22 (Figure 5 and Scheme 6). The number of electrons was determined by rotating disk electrode (RDE) analysis, which showed these redox processes corresponded to $1 \mathrm{e}^{-}, 1 \mathrm{e}^{-}$, and $2 \mathrm{e}^{-}$transfer. As for the CV of $\mathbf{5}$ and $\mathbf{6}$, they have five and six singleelectron transfer processes, respectively, and these are related to the number of corner sulfide linker atoms. In the case of $\mathbf{7}$,
$E_{1}$ involves a two-electron transfer, and hence a total oxidation of seven electrons was observed. Interestingly, the $E_{1}$ values of 5 and 7 were more positive than those of $\mathbf{4}$ and $\mathbf{6}$. This difference could be attributed to the parity of the unit number for the cyclic homologue, i.e. the energy level of the HOMO in cyclic pentamer (5) and heptamer (7) is somewhat lower than those in cyclic tetramer (4) and hexamer (6) due to restricted conjugation in the folded structure of odd-numbered thiacalix[n]DTT derivatives. (a)

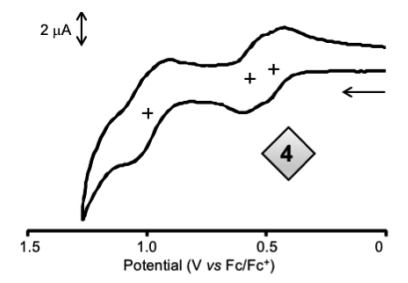

(c)

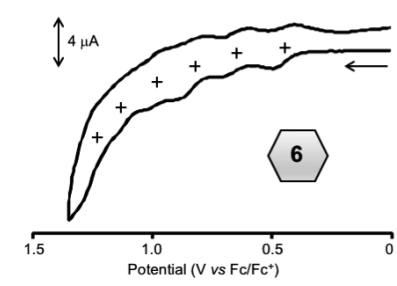

(b)

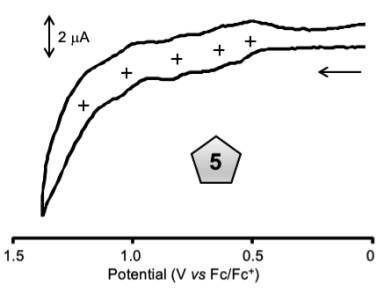

(d)

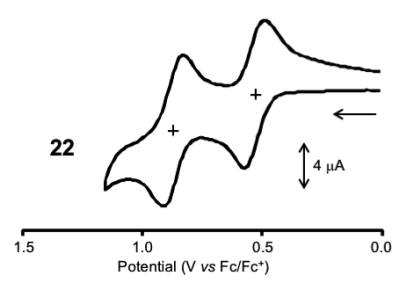

Figure 5. CV of 4, 5, 6, and 22 in 1,2-dichloroethane.

\section{Complexation}

Calix[n]arene and its analogues are considered to be excellent candidate artificial receptors for fullerene $\left(\mathrm{C}_{60}\right) .^{31-36}$ Although thiacalix[n]thiophenes do not form a complex, larger macrocycles formed stable complexes. Remarkable complexations of 5 and $\mathbf{6}$ with $\mathrm{C}_{60}$ are observed both in ${ }^{1} \mathrm{H}$ NMR and electronic spectra. In the ${ }^{1} \mathrm{H}$ NMR spectra, the singlet peak assigned to TMS groups for both $\mathbf{5}$ and $\mathbf{6}$ exhibited obvious downfield shifts upon mixing with $\mathrm{C}_{60}\left(>4\right.$ equiv) in $\mathrm{CDCl}_{3}$. Furthermore, clear upfield shifts of the signal due to $\mathrm{C}_{60}$ were found in the ${ }^{13} \mathrm{C}$ NMR spectra.

In electronic spectra, a weak charge transfer (CT) absorption band was found in the range $\lambda=400-650 \mathrm{~nm}$ when $\mathrm{C}_{60}$ was added to a solution of $\mathbf{5}$ or $\mathbf{6}$ in $\mathrm{PhCl}$. The association constants $\left(K_{\mathrm{a}}\right)$ were estimated from the change in CT absorption in the titration, and were to be $(1.6 \pm 0.1) \times 10^{3} \mathrm{M}^{-1}$ for 5 and $(5.3 \pm 0.4) \times 10^{4} \mathrm{M}^{-1}$ for $\mathbf{6}$. The larger $K_{\mathrm{a}}$ value for $\mathbf{6}$ is attributed to its suitable size and cavity shape. From DFT calculations, the diameter was calculated to be $1.55 \mathrm{~nm}$ for the $D_{3 \mathrm{~d}}$ alternate structure of $\mathbf{6}$, and hence the cavity is large enough to incorporate $\mathrm{C}_{60}$ through $\pi-\pi$ interactions. On the other hand, the folded geometry of $\mathbf{5}$ is less favorable for complexation with $\mathrm{C}_{60}$.

While compound $\mathbf{4}$ did not form a complex in solution, simple diffusion in a triple-layered system composed of $\mathrm{C}_{60}$ in xylene, 1,4-dioxane as middle layer, and $\mathbf{4}$ in $\mathrm{CS}_{2}$ gave a complex easily (Figure 6a). After a few weeks, black single crystals of $4-\mathrm{C}_{60}$ complex were obtained in almost quantitative yield. As shown in Figure $6 \mathrm{~b}$, the crystal contains $\mathbf{4}$ and two $\mathrm{C}_{60}$ along with disordered xylene. Crystallization is in the tetragonal I-4 space group. Thus, the crystal lattice has an $S_{4}$ 
improper rotation axis at the center of $\mathbf{4}$. Two crystallographically identical $\mathrm{C}_{60}$ molecules are located in two cavities, one on either side of compound 4. Although there are no obvious contacts shorter than the sum of van der Waals radii between 4 and the $\mathrm{C}_{60}$ molecules, two DTT moieties are close to $\mathrm{C}_{60}$, and therefore to some extent contribution of sulfur $-\pi$ or $\pi-\pi$ interactions can be considered. Two xylene molecules are adhered onto $\mathrm{C}_{60}$ with van der Waals contacts. In the packing motif, $\mathrm{C}_{60}$ and $\mathbf{4}$ form a columnar array along the $c$-axis (Figure $6 \mathrm{~d}$ ). The highly symmetrical cavity on 4 led to a well-ordered $\mathrm{C}_{60}$ array in the solid state through a simple crystallization method. Although several complexes of macrocyclic compounds with $\mathrm{C}_{60}$ in 1:2 ratio have been reported, ${ }^{33,37}$ there are few studies that clarified the crystal structure of the highly symmetrical complexes. ${ }^{38}$ Further studies on electrical transportation and energy transfer are currently under way. (a)

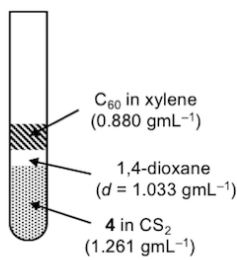

(b)

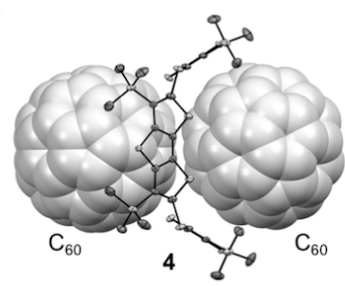

(c)

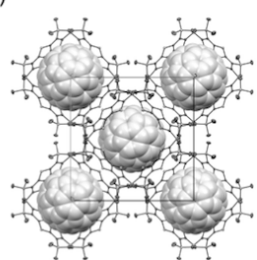

(d)

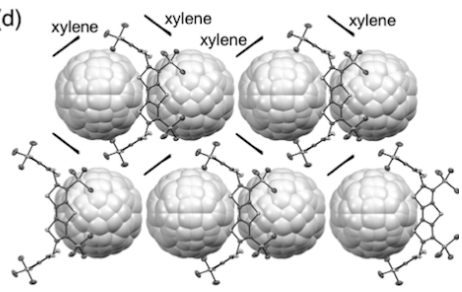

Figure 6. (a) Schematic illustration of recrystallization in a triplelayer system in a test tube. (b) Crystal structure of $\mathbf{4} \cdot 2 \mathrm{C}_{60}$ (The two $\mathrm{C}_{60}$ are drawn as space filling models). (c) Packing diagram in a projection on the $b c$ plane and (d) along the $c$-axis.

\section{Application to Selenium Isologues}

Next, we applied this cyclization method to prepare selenium-containing analogues of these macrocyclic compounds. Organoselenium compounds are of considerable importance due to their potential applications as biologically active molecules and pharmaceuticals. ${ }^{39,40}$ In addition, a wide variety of $\pi$-conjugated compounds containing selenium atoms have been prepared as potentially electric conductive organic materials, and novel host compounds for metal ions. ${ }^{41-45}$ Thanks to their large van der Waals radius, selenium atoms can serve as a robust packing force for supramolecular 3D networks in the solid state. ${ }^{46}$ This network can facilitate hole/electron transportation in the solid state. Thus, the selenium isologue of thiacalix[n]thiophenes is an attractive target. ${ }^{47,48}$

A great many well-established methods for the formation of the Ar-Se bonds in diarylselenides have been developed. In earlier days, the nucleophilic substitution reactions of an organometallic reagent with a Se source were utilized. The treatment of an aryllithium (Ar-Li) or a Grignard reagent $(\mathrm{Ar}-\mathrm{MgX})$ with $\mathrm{SeCl}_{2}{ }^{49}$ or $\mathrm{Ar}-\mathrm{Se}-\mathrm{Se}-\mathrm{Ar}^{50}$ system gave a symmetrical/non-symmetrical diarylselenide compound. Later, the two groups of Nishiyama ${ }^{51}$ and Beletslkaya ${ }^{52}$ independently reported the coupling reaction of phenyl tributylstannyl sele- nide $\left(\mathrm{PhSeSnBu}_{3}\right)$ with $\mathrm{Ar}-\mathrm{X}(\mathrm{X}=\mathrm{Cl}, \mathrm{Br}$, OTf $)$ to form $\mathrm{ArSePh}$ in the presence of $\mathrm{Pd}$ or $\mathrm{Ni}$ as a catalyst at almost the same time.

Bis(tributyltin)selenide, $\left(\mathrm{Bu}_{3} \mathrm{Sn}\right)_{2} \mathrm{Se}$, can be prepared by the literature procedure reported by Segi and co-workers. ${ }^{53}$ It was synthesized simply in multigram amounts by mixing elemental selenium and $\mathrm{Bu}_{3} \mathrm{SnCl}$ under basic conditions, and it can be stored stably in a sealed ampoule for more than a year. The coupling reaction to form a symmetrical selenium ether (Ar$\mathrm{Se}-\mathrm{Ar})$ using $\left(\mathrm{Bu}_{3} \mathrm{Sn}\right)_{2} \mathrm{Se}$ was first reported by Nishiyama and co-workers. ${ }^{54}$ However, only the reaction employing iodobenzene to give diphenyl selenide in low yield had been reported. Thus, initially we optimized reaction conditions for our planned cyclization reactions (Table 4).

Table 4. Palladium-catalyzed reaction of $\mathrm{Ar}-\mathrm{X}$ with $\left(\mathrm{Bu}_{3} \mathrm{Sn}\right)_{2} \mathrm{Se} .^{a}$

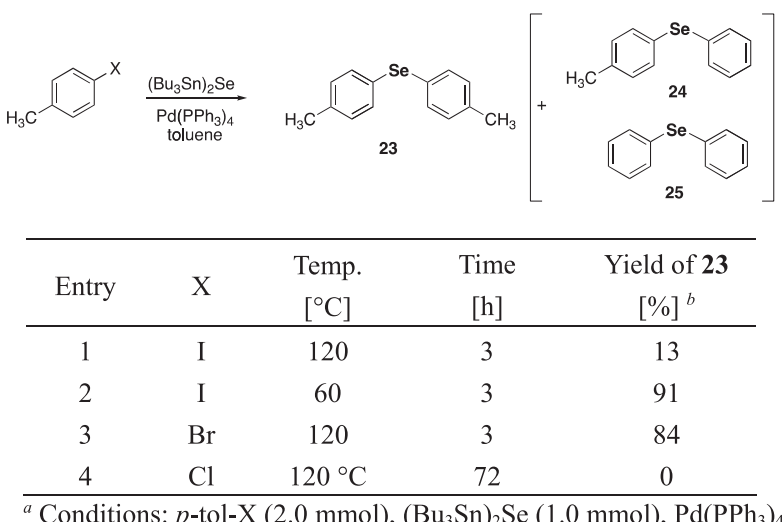

$(0.10 \mathrm{mmol})$, and toluene $(2 \mathrm{~mL}) .{ }^{b}$ Isolated yield.

When 4-iodotoluene reacts with $\left(\mathrm{Bu}_{3} \mathrm{Sn}\right)_{2} \mathrm{Se}$ in the presence of $\mathrm{Pd}\left(\mathrm{PPh}_{3}\right)_{4}$ at $120{ }^{\circ} \mathrm{C}$, the previously reported conditions, ${ }^{54}$ 23 was obtained in yield 13\%. Diphenyl selenide (24) and phenyl( $p$-tolyl)selenide (25) were obtained as major products (entry 1). The phenyl ring(s) may originate from the $\mathrm{PPh}_{3}$ ligand on the catalyst. A similar rearrangement was reported in previous literature when the reaction was performed at higher temperature. ${ }^{55}$ In fact, when the coupling reaction was carried out at $60{ }^{\circ} \mathrm{C}, \mathbf{2 3}$ was obtained in $91 \%$ (entry 2). On the other hand, the initial yield was improved, even at higher temperature, when 4-bromotoluene (entry 3) was employed as the starting compound. Next, we evaluated the scope of this transformation for preparing diverse diarylselenides. Various diarylselenides were obtained in good yield (84-99\%) (Scheme 7).

This coupling method was also applicable to the synthesis of the desired macrocyclic selenium isologues. Thus, the coupling of $\left(\mathrm{Bu}_{3} \mathrm{Sn}\right)_{2} \mathrm{Se}$ and dibromoselenophene (34) or diboromoDTT derivative (18) gave macrocycles 11-13 or 14 in moderate to good yield (Scheme 8). In the synthesis of 11-13, only the cyclic tetramer $\mathbf{1 1}$ was isolated in pure form after GPC separation, although the presence of $\mathbf{1 2}$ and $\mathbf{1 3}$ were confirmed by MS and ${ }^{1} \mathrm{H},{ }^{13} \mathrm{C},{ }^{77} \mathrm{Se}$ NMR spectra of the mixture. As for the synthesis of $\mathbf{1 4}$, only cyclic tetramer was obtained in $29 \%$, together with acyclic products. The lowering of the reaction yield compared to that of thiacalix[n]DTT is presumably due to the narrower angle of the $\mathrm{C}-\mathrm{Se}-\mathrm{C}$ hinge, and longer $\mathrm{C}-\mathrm{Se}$ bond length.

The molecular structure obtained from $\mathrm{X}$-ray crystallographic analysis of $\mathbf{1 1}$ shows a large cavity surrounded by four 
Scheme 7. Palladium-catalyzed coupling reaction of $\mathrm{Ar}-\mathrm{X}$ with $\left(\mathrm{Bu}_{3} \mathrm{Sn}\right)_{2} \mathrm{Se}$.

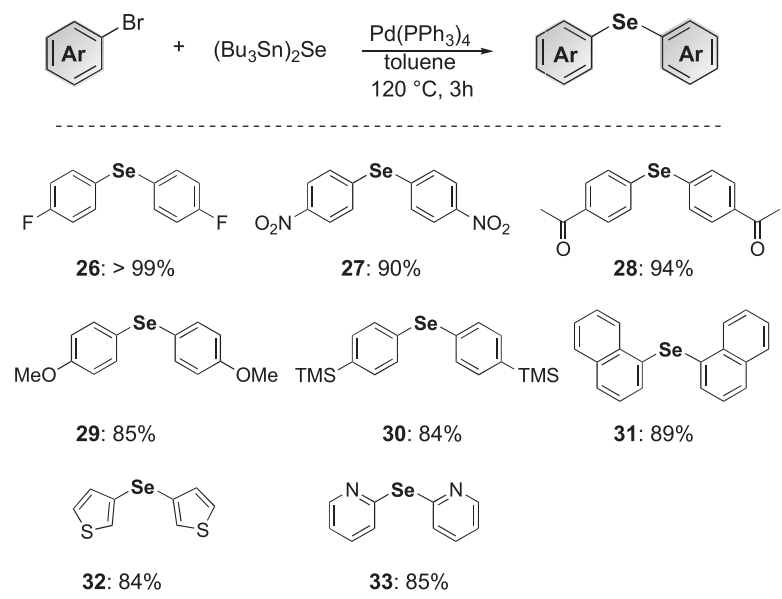

Scheme 8. Synthesis of selenacalix[n]selenophene 11-13 and selenacalix[4]DTT 14. The yields of 12 and 13 were estimated by ${ }^{1} \mathrm{H}$ NMR spectra.
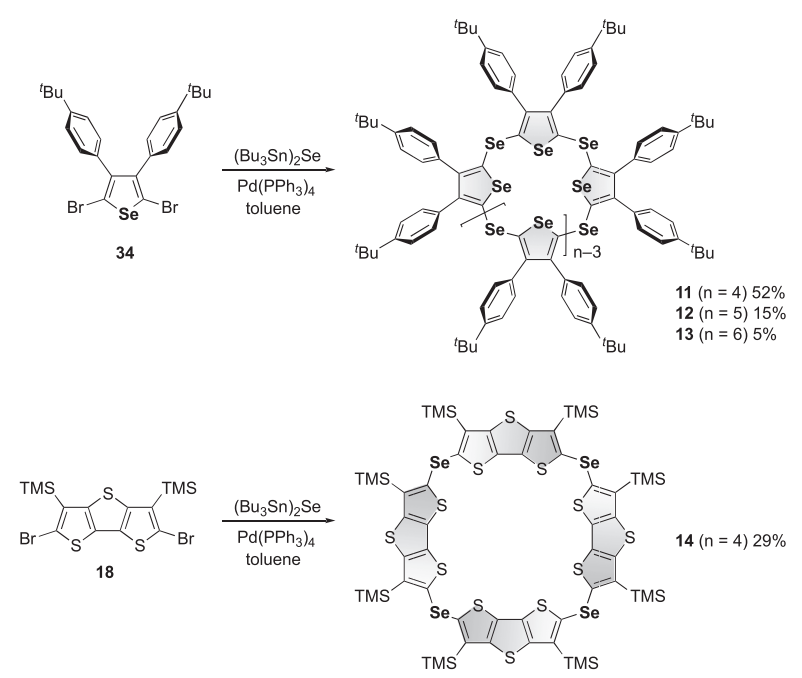

selenophene units (Figure 7). In contrast to thiacalix[n]thiophene derivatives, one pair of opposed selenophenes are embedded horizontally, while the other are positioned vertically to the cavity. This conformation is expected to have large strain compared with the most stable 1,3-alternate conformer owing to steric hindrance resulting from the tert-butylphenyl substituents. This apparently unstable geometry is attainable due to the contribution of intermolecular $\mathrm{Se} \cdots \pi$ and $\mathrm{Se} \cdots \mathrm{Se}$ interactions between the proximal selenacalix[4]selenophenes. These attractive contacts enable the formation of a onedimensional columnar array of $\mathbf{1 1}$ along the $a$-axis in the crystal structure (Figure 7b). The crystals also contain hexane molecules, derived from the poor solvent in the recrystallization procedure, around the columnar array to form a tubularlike arrangement.

As for X-ray analysis of $\mathbf{1 4}$, a quite similar crystal structure to that of $\mathbf{4}$ was obtained. Compound $\mathbf{1 4}$ adopts a 1,3alternate type conformation (Figure 8). Interestingly, $\mathbf{1 4}$ forms a repetitive porous structure containing a large cavity with a diameter of $c a .8 .6 \AA$. This porous network is sustained by self-complementary $\mathrm{Se} \cdots \pi$ interactions. Calculation of the void space present in the crystal structure indicated a onedimensional nanoporous array with a large void volume of (a)

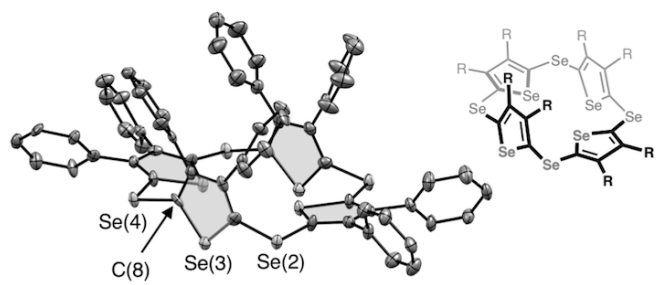

(b)

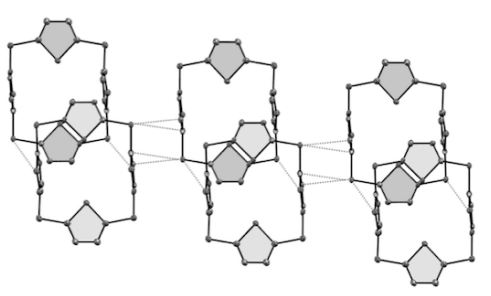

(c)

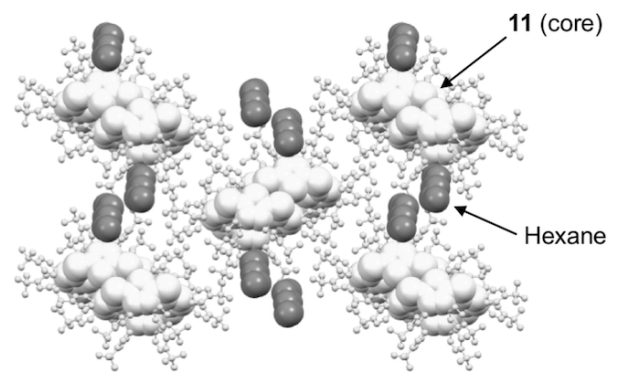

Figure 7. (a) ORTEP drawing of $\mathbf{1 1}\left({ }^{t} \mathrm{Bu}\right.$ groups and hydrogen atoms are omitted for clality.) (b) Crystal packing diagram. Dash lines indicate van der Waals contacts between $\mathrm{Se} \cdots \mathrm{Se}$ or $\mathrm{Se} \cdots \mathrm{C}$. (c) Molecular arrangement of the selenophene core (light gray sphere), ${ }^{t} \mathrm{Bu}$ groups (ball), and hexane (gray sphere). (reproduced with permission from ref. 19). (a)

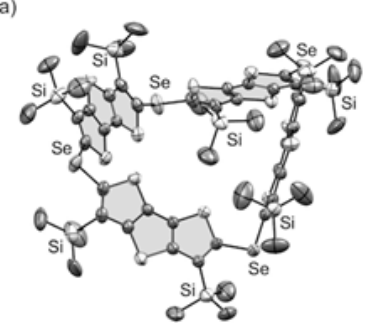

(b)

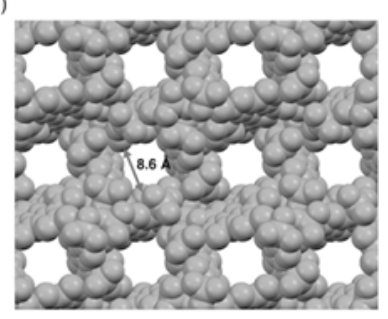

Figure 8. (a) ORTEP drawing of 14. (b) Large void cavity in the packing diagram. (reproduced with permission from ref. 20).

2,506 $\AA^{3}$ within a unit cell $\left(10,097 \AA^{3}\right)$.

\section{Supramolecular Gel Formation}

In general, it is known that calix[n]arenes bearing hydrogen-bonding units occasionally create supramolecular selfassembly leading to gelling phenomena. ${ }^{56-59}$ However, to our surprise, some thiacalix[4]thiophene and selenacalix[4] selenophenes also showed gelling properties, although they do not have any hydrogen bonding sites. A simple protocol of heating-cooling a toluene solution of $1 \mathrm{e}\left(\mathrm{R}={ }^{t} \mathrm{Bu}\right)$ gave an opaque gel (Figure 9a). The critical gel concentration (CGC) in toluene was determined to be $6.6 \mathrm{wt} \%$. Similar behavior was found in $\mathrm{PhCl}$ solution. Scanning electron microscope (SEM) observation of its xerogel revealed that the gel is composed of retiform entangled fibrous rods (Figure 9b). Other thiacalix[4]thiophenes $\mathbf{1 b}$-d showed no gelling properties due to their high solubility in common organic solvents. 

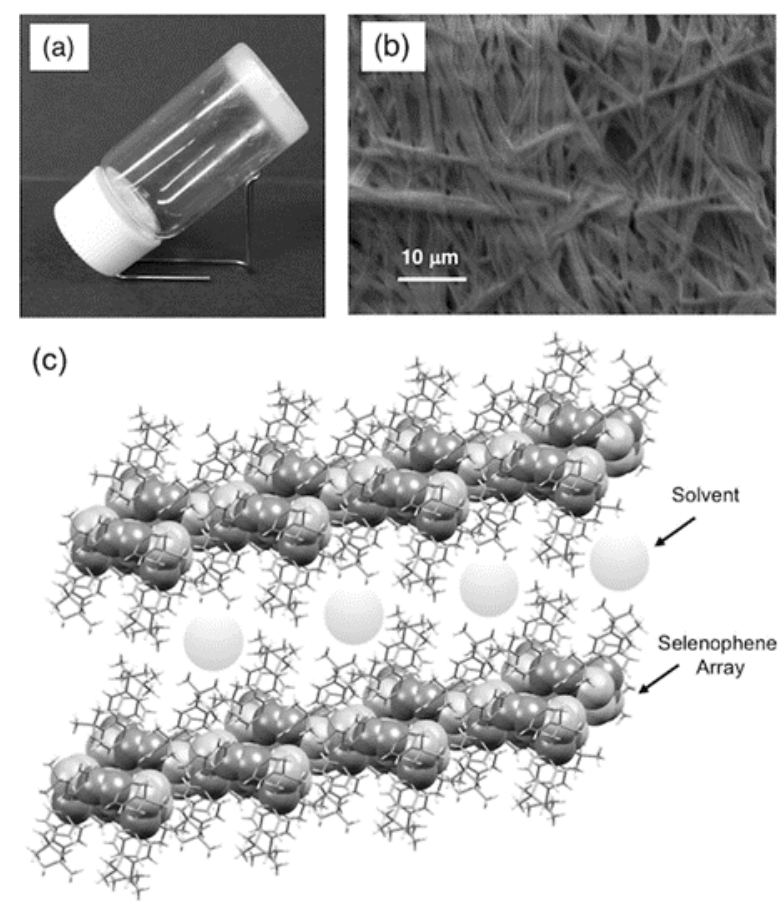

Figure 9. (a) Photo of the gel of 1e (from toluene). (b) SEM image obtained from the air-dried xerogel of 1e. (c) Schematic illustration of the possible molecular array in the gel of $\mathbf{1 1}$ The arrays are based on the single crystal X-ray analysis. ((a) and (b) reproduced with permission from ref. 16).

In addition, selenacalix[4]selenophene $\mathbf{1 1}$ also possesses gelling ability. While compound $\mathbf{1 1}$ was soluble in common organic solvents, a pale-yellow gel was formed from toluene. The CGC value was calculated to be $15 \mathrm{wt} \%$. X-ray diffraction (XRD) analysis of the xerogel of $\mathbf{1 1}$ revealed a peak in the small angle region at $2 \theta=4.8^{\circ}(d=18.4 \AA)$. Interestingly, this diffraction peak of the gel was similar to the peak corresponding to the (011) and (020) planes estimated from the single crystal of 11. Hence, the pale-yellow gel obtained and the single crystal should have similar molecular arrangements, where intermolecular van der Waals contacts promote one-dimensional elongation to cause self-assembly, and there is resultant vacant space for solvents. Again, these thiacalix[4]thiophenes and seleanacalix[4]selenophene have no $\mathrm{H}$-bonding site, and therefore, self-assembly driven by robust intermolecular interactions of sulfur or selenium atoms could be essential for the formation of the gel in this system. Although the gelation ability of these macrocycles is relatively low, the molecular design is quite different from that of conventional low molecular mass gelators derived from self-assembly based on $\mathrm{H}$-bonding. Hence, the present supramolecular gel may pave the way to novel functional nanostructures having electron-conducting properties.

\section{Conclusion and Outlook}

Inspired by the scalable preparation of calix[n]arene, we have developed a simple synthesis of thiacalix[n]thiophene and its analogues by using the $\mathrm{Pd}$-catalyzed coupling reaction with tributyltinchalcogenide $\left(\mathrm{Bu}_{3} \mathrm{Sn}\right)_{2} \mathrm{Ch}(\mathrm{Ch}=\mathrm{S}$ or $\mathrm{Se})$. In this cyclization, substituents at the $\beta$ position of thiophene and DTT played a key role. Although several thiacalix[n]arene (cyclic thioaromatic ether) analogues have been prepared via substitution reactions, the present macrocyclization can be car- ried out under neutral conditions. The molecular structures of the cyclic homologues depend on their substituents and the parity of unit number in the homologue; even-numbered macrocycles with large substituents tend to form an alternate conformer, while odd-numbered macrocycles form a folded geometry. In electrochemical studies using CV and DPV, all macrocycles underwent a multi-redox process depending on the number of sulfide linkages. The macrocycles form a complex with $\mathrm{C}_{60}$ molecules in solution or in the solid state. Thiacalix[4]DTT derivative $\mathbf{4}$ captured two $\mathrm{C}_{60}$ in the cavity, while $\mathbf{5}$ and 6 formed a 1:1 complex. We also demonstrated gelling phenomena of for thiacalix[4]thiophene 1e and selenacalix[n]selenophene 11 despite their lack of $\mathrm{H}$-bonding sites. We deduced that the mechanism of gel formation is through robust intermolecular self-assembly thanks to the attractive contacts of sulfur or selenium. To the best of our knowledge, there have been no other reports of organic gelators based on calix[4]arene without $\mathrm{H}$-bonding units.

The search for efficient syntheses of cyclic compounds consisting of $\pi$-conjugated systems has long been a subject of importance to synthetic organic chemists. A variety of aesthetically pleasing cyclic molecules has been synthesized after the conquest of many synthetic difficulties. On the other hand, as seen with calix[n]arene and its families, we already know that some actual combinations of aromatic unit and angular linker predominantly give macrocycles despite their entropic disadvantage. In the future, it may become easy to uncover new combinations for efficient cyclization strategies leading to fascinating functionalized compounds by using chemoinformatics methods supported by deep-learning techniques. However, at the present stage, there seems to be a great lack of reliable training data for this kind of machine learning methodology. The present approach, which we call "dancing with sulfur", and which employs divalent sulfur as an angular linker, limits the degree of freedom in the elongation process, and hence we are convinced that our findings will serve as relevant pre-training data for the promotion of such new chemistry.

\section{Acknowledgements}

The author would like to thank Prof. Dr. Yasuhiro Mazaki and all the group members at Kitasato University. In particular, Dr. Ryota Inoue (AIST), Mr. Yoshiki Honda, Mr. Kazuhiro Takahashi, Mr. Daisuke Watanabe, and Mr. Takumi Hirokawa worked together on this project. The author also acknowledges Prof. Dr. Tohru Nishinaga (Toyko Metropolitan University), Prof. Dr. Turan Oztruk (Isutanbul Institute of Technology), and Dr. Minami Kato (AIST) for their helpful discussion and collaboration. This work was supported by Grant-in-Aids of JSPS for Young Chemist (B) (Nos. JP26810025, JP16K17871), Grant-in-Aids of JSPS for Scientific Research (C) JP18K05092. The contributions from the Mazda Foundation, a Daicel Chemical Industry Award from the Society of Synthetic Organic Chemistry (Japan), and the research grant from Kitasato Research Center for Environment Science are all acknowledged. All calculations were performed at the Research Center for Computational Science, Okazaki (Japan).

\section{References}

1) Cavil, E. Science 1983, 219, 1177

2) Neri, P.; Sessler, J. L.; Wang, M. X. Calixarenes and Beyond; Springer: 
Switzerland, 2016.

3) Davis, F.; Higson, S. Macrocycles: Construction, Chemistry, and Nanotechnology Applications; Wiley, 2011.

4) Morohashi, N.; Narumi, F.; Iki, N.; Hattori, T.; Miyano, S. Chem. Rev. 2006, 106, 5291.

5) Kumagai, H.; Hasegawa, M.; Miyanari, S.; Sugawa, Y.; Sato, Y.; Hori, T.; Ueda, S.; Kamiyama, H.; Miyano, S. Tetrahedron Lett. 1997, 38, 3971

6) Vögtle, F. Tetrahedron Lett. 1984, 25, 3445

7) Guo, Q. H.; Zhao, L.; Wang, M. X. Chem. Eur. J. 2016, 22, 6947.

8) Guo, Q.-H.; Fu, Z.-D.; Zhao, L.; Wang, M.-X. Angew. Chem. Int. Ed. 2014, 53, 13548

9) Iyoda, M.; Shimizu, H. Chem. Soc. Rev. 2015, 44, 6411.

10) Aoyama, Y.; Tanaka, Y.; Toi, H.; Ogoshi, H. J. Am. Chem. Soc. 1988, $110,634$.

11) Ogoshi, T.; Yamagishi, T. A.; Nakamoto, Y. Chem. Rev. 2016, 116, 7937.

12) Shi, T. H.; Guo, Q. H.; Tong, S.; Wang, M. X. J. Am. Chem. Soc. 2020, 142, 4576.

13) König, B.; Martin, R.; Dix, I.; Jones, P. G. J. Chem. Res. (S) 1997, 69

14) Nakayama, J.; Kataono, N.; Sugihara, Y.; Ishii, A. Chem. Lett. 1997, 897.

15) Katano, N.; Sugihara, Y.; Ishii, A.; Nakayama, J. Bull. Chem. Soc Jpn. 1998, 71, 2695.

16) Hasegawa, M.; Honda, Y.; Inoue, R.; Mazaki, Y. Chem. Asian J. 2016, 11,674 .

17) Hasegawa, M.; Inoue, R.; Mazaki, Y. Synlett 2016, 27, 2407.

18) Inoue, R.; Hasegawa, M.; Nishinaga, T.; Yoza, K.; Mazaki, Y. Angew. Chem. Int. Ed. 2015, 54, 2734.

19) Hasegawa, M.; Haga, S.; Nishinaga, T.; Mazaki, Y. Org. Lett. 2020, 22,3755 .

20) Hasegawa, M.; Takahashi, K.; Inoue, R.; Haga, S.; Mazaki, Y. Chem. Asian J. 2019, 14, 1647.

21) Procter, D. J. J. Chem. Soc. Perkin 1, 2001, 4, 335.

22) Percec, V.; Bae, J. Y.; Hill, D. H. A. J. Org. Chem. 1995, 60, 6895.

23) Cristau, H. J.; Chabaud, B.; Labaudiniere, R.; Christol, H. Organometallics 1985, 4, 657

24) Li, Y.; Nie, C.; Wang, H.; Li, X.; Verpoort, F.; Duan, C. Eur. J. Org. Chem. 2011, 7331

25) Correa, A.; Carril, M.; Bolm, C. Angew. Chem. Int. Ed. 2008, 47, 2880 .

26) Wong, Y. C.; Jayanth, T. T.; Cheng, C. H. Org. Lett. 2006, 8, 5613.

27) Kosugi, M.; Ogata, T.; Terada, M.; Sano, H.; Migita, T. Bull. Chem. Soc. Jpn. 1985, 58, 3657

28) Mazaki, Y.; Kobayashi, K. Tetrahedron Lett. 1989, 30, 3315.

29) Cinar, M. E.; Ozturk, T. Chem. Rev. 2015, 115, 3036.

30) Frey, J.; Bond, A. D.; Holmes, A. B. Chem. Commun. 2002, 2424

31) Atwood, J. L.; Koutsantonis, G. A.; Raston, C. L. Nature 1994, 368, 229.

32) Suzuki, T.; Nakashima, K.; Shinkai, S. Chem. Lett. 1994, 699.

33) Atwood, J. L.; Barbour, L. J.; Colin, L.; Sudria, I. B. N. Angew. Chem. Int. Ed. 1998, 37, 981

34) Haino, T.; Yanase, M.; Fukazawa, Y. Angew. Chem., Int. Ed. Engl. 1997, 36, 1996.

35) Hirao, T.; Fukuta, K.; Haino, T. Macromolecules 2020, 53, 3563.

36) Fa, S. X.; Wang, L. X.; Wang, D. X.; Zhao, L.; Wang, M. X. J. Org. Chem. 2014, 79, 3559.

37) Song, J.; Aratani, N.; Shinokubo, H.; Osuka, A. Chem. Sci. 2011, 2 , 748.

38) Xue, S.; Kuzuhara, D.; Aratani, N.; Yamada, H. Org. Lett. 2019, 21, 2069

39) Nogueira, C. W.; Zeni, G.; Rocha, J. B. T. Chem. Rev. 2004, 104, 6255.

40) Manjare, S. T.; Kim, Y.; Churchill, D. G. Acc. Chem. Res. 2014, 47, 2985.
41) Thomas, J.; Maes, W.; Robeyns, K.; Ovaere, M.; Van Meervelt, L.; Smet, M.; Dehaen, W. Org. Lett. 2009, 11, 3040

42) Thomas, J.; Dobrzańska, L.; Van Hecke, K.; Sonawane, M. P.; Robeyns, K.; Van Meervelt, L.; Woźniak, K.; Smet, M.; Maes, W.; Dehaen, W. Org. Biomol. Chem. 2012, 10, 6526.

43) Van Rossom, W.; Thomas, J.; Terentyeva, T. G.; Maes, W.; Dehaen, W. Eur. J. Org. Chem. 2013, 2085.

44) Takimiya, K.; Otsubo, T. Selenophenes as Hetero-Analogues of Thiophene-Based Materials. In Handbook of Thiophene-based Materials: Applications in Organic Electronics and Photonics Vol. 1; Perepichka, F. I., Perepichka, F. D., Eds.; Wiley: Chichester, 2009; p 321.

45) Xu, W.; Wu, L.; Fang, M.; Ma, Z.; Shan, Z.; Li, C.; Wang, H. J. Org. Chem. 2017, 82, 11192

46) Hasegawa, M.; Kobayakawa, K.; Nojima, Y.; Mazaki, Y. Org. Biomol. Chem. 2019, 17, 8822.

47) Kumar, P.; Kashid, V. S.; Mague, J. T.; Balakrishna, M. S. Tetrahedron Lett. 2014, 55, 5232 .

48) Kunnari, S. M.; Oilunkaniemi, R.; Laitinen, R. S.; Ahlgren, M. Acta Crystallogr. Sect. C Cryst. Struct. Commun. 2002, 58, o610.

49) Zade, S. S.; Panda, S.; Singh, H. B.; Wolmershäuser, G. Tetrahedron Lett. 2005, 46, 665.

50) Kumar, S.; Engman, L. J. Org. Chem. 2006, 71, 5400.

51) Nishiyama, Y.; Kawamatsu, H.; Funato, S.; Tokunaga, K.; Sonoda, N. J. Org. Chem. 2003, 68, 3599 .

52) Beletskaya, I. P.; Sigeev, A. S.; Peregudov, A. S.; Petrovskii, P. V. J. Organomet. Chem. 2000, 605, 96.

53) Maeda, H.; Takashima, M.; Sakata, K.; Watanabe, T.; Honda, M.; Segi, M. Tetrahedron Lett. 2011, 52, 415.

54) Nishiyama, Y.; Tokunaga, K.; Sonoda, N. Org. Lett. 1999, 1, 1725.

55) Goodson, F. E.; Wallow, T. I.; Novak, B. M. J. Am. Chem. Soc. 1997, $119,12441$.

56) Duy, L. N.; Sekiya, R.; Tosaka, M.; Yamago, S.; Matsumoto, T.; Nishino, T.; Ichikawa, T.; Haino, T. Chem. Lett. 2019, 48, 43.

57) Xing, B.; Choi, M. F.; Zhou, Z.; Xu, B. Langmuir 2002, 18, 9654

58) Lee, J. H.; Park, J.; Park, J. W.; Ahn, H. J.; Jaworski, J.; Jung, J. H. Nat. Commun. 2015, 6, 1 .

59) Su, P. M.; Chang, K. C.; Yang, C. J.; Liu, Y. C.; Chung, W. S. Chem Commun. 2017, 53, 13241.

\section{PROFILE}

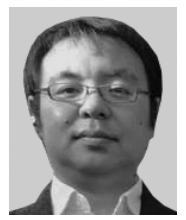

Masashi Hasegawa received his B.S. in 2000 and Ph.D. in 2004 from Tokyo Metropolitan University under the supervision of Professor Masahiko Iyoda. Thereafter, he undertook postdoctoral research with Professor Timothy M. Swager at Massachusetts Institutes of Technology, and Professor Yohji Misaki at Ehime University, Japan. His research interests are in the synthesis of aesthetic molecules based on novel $\pi$-systems and their applications to material science. His subsequent research has been recognized with a Daicel Chemical Industry Award in Synthetic Organic Chemistry, Japan (2010), Mazda Foundation Award (2009), and BCSJ Award (2011). 